\section{Pseudodentritic keratitis associated with meibomitis in young healthy males}

\begin{abstract}
Purpose To report unusual corneal manifestations of pseudodendritic keratitis in cases of coexisting meibomian gland dysfunction (MGD).

Methods Retrospective chart review of five cases of MGD with associated atypical corneal lesions was carried out. Information including patient's age, symptoms and their duration, clinical features, methods of diagnosis, treatment, and outcome were abstracted from the medical records. Pseudodendritic keratitis and MGD was defined before the data collection.

Results All five patients were males within the age range of 6-24 years. Common symptoms were irritation and watering. MGD, which was defined as stenosis of meibomian gland orifices and/or turbid meibomian secretions, was seen in all the patients. Corneal lesions were epithelial, raised and dendritic in morphology. Blood investigations carried out to rule out tyrosinemia in three of the patients were negative. Bandage contact lens facilitated disappearance of these lesions in five eyes.

Conclusions Corneal involvement in the form of pseudodendritic keratitis may be associated with MGD. Application of bandage contact lens facilitated prompt resolution, suggesting mechanical factor with or without other etiological factors may be at interplay in producing these innocuous corneal lesions. Eye (2007) 21, 826-828; doi:10.1038/sj.eye.6702373; published online 28 July 2006
\end{abstract}

2005

Accepted in revised form: 8 March 2006

Published online: 28 July 2006

Proprietary interest: None Financial Support: Hyderabad Eye Research Foundation, Hyderabad, India
V Jain, MS Sridhar, PK Vaddavalli and V Sangwan

characterized by linear branching epithelial

lesions with terminal bulbs and swollen borders that contain live virus. It represents a true ulcer in that it extends through the basement membrane and stain with fluorescein.

Numerous other epithelial lesions that simulate true dendritic ulcer morphologically have been referred to as 'pseudodendritic keratitis' to distinguish them from the lesions caused by HSV.

Recently healed epithelial defects, varicella zoster keratitis $^{2,3}$ and epithelial lesions of tyrosinemia type II (the Richner-Hanhart syndrome $)^{4}$ are the common corneal lesions resembling true dendritic ulcers. However, these can be differentiated from HSV dendrites as they are raised and not ulcerated and do not stain with fluorescein. Through this communication, we report morphologically similar lesions in the cornea seen in healthy young males in association with meibomian gland dysfunction (MGD).

\section{Materials and methods}

Retrospective chart review of five cases of MGD with associated corneal epithelial lesions was carried out. Information including patient's age, symptoms and their duration, clinical features, methods of diagnosis, treatment, and outcome were abstracted from the medical records. Pseudodendritic keratitis and MGD was defined before the data collection.

Pseudodendritic keratitis was defined as raised, branching, epithelial lesions with/or without associated punctate epithelial staining. Staining along the entire length was absent. MGD was characterized by turbid meibomian gland secretions with orifice stenosis with or without associated telangiectasia of the lid margins. Detailed ocular and systemic examination was performed. Appropriate laboratory and microbiological investigations were carried out. 


\section{Results}

The case summaries are elaborated in Table 1 . All patients were young males with age ranging from 6 to 30 years. All patients had bilateral disease, except for case 5 , in which only right eye was involved. The common symptoms were irritation and watering. All patients had typical corneal epithelial lesions with associated MGD as has been defined. Corneal epithelial lesions were usually seen in the central (Figure 1) and inferotemporal quadrants. Punctate corneal fluorescein staining was seen. Rose Bengal staining was not performed. Mild superficial conjunctival

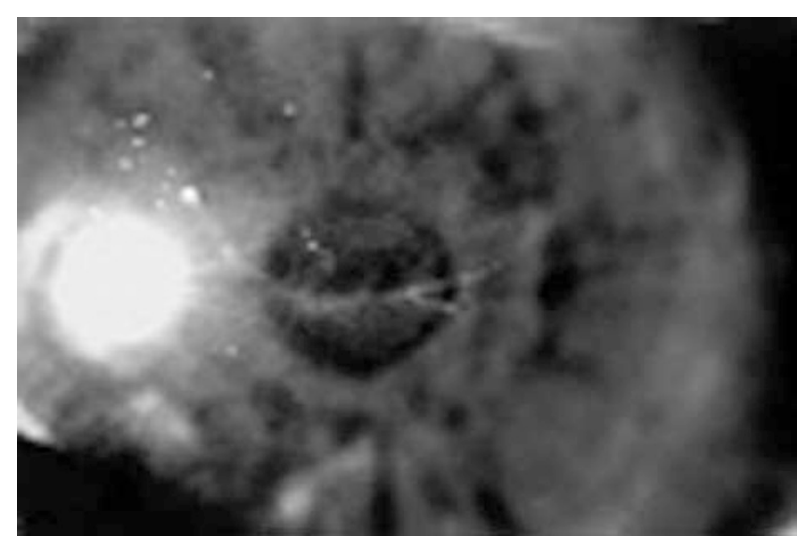

Figure 1 Diffuse slit-lamp view of patient no. 1, showing corneal epithelial branching lesion located in the central cornea. congestion was also noted. Tear function tests could not be performed during initial evaluation owing to the presence of corneal lesions and patient symptomatology. There was no evidence of corneal dystrophies and other systemic corneal epithelial abnormalities.

Systemic evaluation did not reveal any abnormality and there was no history of any drug usage. There was no history of prior similar complaints or of any ocular trauma. In three patients (cases 1, 2, and 3), blood investigations were carried out to rule out tyrosinemia which were negative. Microbiological work-up for HSV-1 including immunofluorescent assay and polymerase chain reaction was negative. Therapy for MGD was prescribed to all the patients comprising of warm compresses, artificial tears, and erythromycin eye ointment. Oral doxycycline $100 \mathrm{mg}$ twice/day was also prescribed in three patients (cases 1, 4, and 5). Two months after the failure of initial therapy, bandage contact lenses were applied in three patients (cases 2, 3, and 4). The lesions resolved after the application of bandage contact lens.

\section{Discussion}

Classic dendritic ulcers caused by HSV have staining properties that help the clinician in arriving at the correct diagnosis. Dendritic ulcer being a true ulcer stains with fluorescein along the entire length of the lesion. However, the swollen epithelial borders are actually

Table 1 Clinical features of patients with meibomian gland disease and pseudodendritic keratitis

\begin{tabular}{|c|c|c|c|c|c|c|c|c|c|c|}
\hline Sl. no. & Age/sex & Symptoms & Duration & $O D$ & OS & Lids & Cornea & Others & Treatment & Follow-up \\
\hline 1 & $15 / \mathrm{M}$ & $\begin{array}{l}\text { Irritation, } \\
\text { watering }\end{array}$ & 10 years & $20 / 30$ & $20 / 20$ & MGD & $\begin{array}{l}\text { Pseudodendrites } \\
\text { (OU) }\end{array}$ & $\begin{array}{l}\text { Normal } \\
\text { serum } \\
\text { tyrosine, } \\
\text { negative } \\
\text { virology } \\
\text { studies }\end{array}$ & $\begin{array}{l}\text { WC, AT, oral } \\
\text { doxycycline, } \\
\text { debridement }\end{array}$ & $\begin{array}{l}\text { Lost to } \\
\text { follow-up }\end{array}$ \\
\hline 2 & $24 / \mathrm{M}$ & $\begin{array}{l}\text { Irritation, } \\
\text { photophobia }\end{array}$ & 10 years & $20 / 40$ & $20 / 40$ & MGD & $\begin{array}{l}\text { Pseudodendrites } \\
\text { (OU) }\end{array}$ & $\begin{array}{l}\text { Normal } \\
\text { serum } \\
\text { tyrosine, } \\
\text { negative } \\
\text { virology } \\
\text { studies }\end{array}$ & $\begin{array}{l}\mathrm{WC}, \mathrm{AT} \\
\mathrm{BCL}+\mathrm{A}\end{array}$ & $\begin{array}{l}\text { Resolved } 5 \text { days } \\
\text { after BCL }\end{array}$ \\
\hline 3 & $6 / \mathrm{M}$ & $\begin{array}{l}\text { Photophobia, } \\
\text { irritation }\end{array}$ & 2 weeks & \multicolumn{2}{|c|}{$\begin{array}{c}\text { Could not } \\
\text { be evaluated }\end{array}$} & MGD & $\begin{array}{l}\text { Pseudodendrites } \\
\text { (OU) }\end{array}$ & $\begin{array}{l}\text { Normal } \\
\text { serum } \\
\text { tyrosine }\end{array}$ & $\begin{array}{l}\text { AT, } \\
\text { erythromycin } \\
\text { syrup, } \\
\text { BCL+A }\end{array}$ & $\begin{array}{l}\text { Lesion absent } \\
\text { after } 1 \text { month }\end{array}$ \\
\hline 4 & $16 / \mathrm{M}$ & $\begin{array}{l}\text { Irritation, } \\
\text { watering, } \\
\text { decreased } \\
\text { vision }\end{array}$ & 1 month & $20 / 100$ & $20 / 100$ & MGD & $\begin{array}{l}\text { Pseudodendrites } \\
\text { (OU) }\end{array}$ & $\begin{array}{l}\text { Negative } \\
\text { virology } \\
\text { studies }\end{array}$ & $\begin{array}{l}\text { WC, oral } \\
\text { doxycycline, } \\
\text { erythromycin } \\
\text { eye Oc, AT, } \\
\text { BCL + A }\end{array}$ & $\begin{array}{l}\text { Resolved } \\
\text { after BCL }\end{array}$ \\
\hline 5 & $30 / \mathrm{M}$ & Irritation & 2 month & $20 / 20$ & $20 / 20$ & MGD & $\begin{array}{l}\text { Pseudodendrites } \\
\text { (OD) }\end{array}$ & $\begin{array}{l}\text { Negative } \\
\text { virology } \\
\text { studies }\end{array}$ & $\begin{array}{l}\text { WC, AT, oral } \\
\text { doxycycline }\end{array}$ & $\begin{array}{l}\text { Resolved in } \\
2 \text { months }\end{array}$ \\
\hline
\end{tabular}

MGD, meibomian gland disease; WC, warm compresses; AT, artificial tears; BCL, bandage contact lens; A, topical antibiotic; Oc, ointment. 
raised, when compared to surrounding epithelium and stain negatively with fluorescein. Rose Bengal, which stains devitalized cells is taken up by the swollen epithelial cells at the ulcer border. ${ }^{1}$

Varicella zoster pseudodendrites can often be misdiagnosed as HSV dendritic ulcer. However, in contrast to HSV dendrites, these lesions have a coarse, blunted appearance, more plaque like, raised above the surface and lack the terminal bulbs. Moreover, as there is no central ulceration, they stain with fluorescein only sparingly and not along the entire length as the true dendrites. Occasionally, wiping zoster pseudodendrites from the corneal epithelium leaves an intact epithelial surface behind unlike simplex dendrites in which a fullthickness epithelial defect is present. Varicella zoster virus has been cultured from some of these lesions. ${ }^{2,3}$

Tyrosinemia type II or Richner-Hanhart syndrome is a systemic oculocutaneous disorder associated with a triad of pseudodendritiform keratitis, hyperkeratotic lesions of palm and sole, and mental retardation. Ocular lesions are bilateral, varying in severity from a mild epithelial pseudodendrite to a geographic lesion with gross corneal clouding. Pseudodendrites may undergo spontaneous remissions and recurrences, may occur without the skin lesions, making the misdiagnosis of herpes simplex keratitis more likely. However, morphologically the lesions of tyrosinemia are thicker and plaque like, failing to demonstrate the fine delicate branching and club-shaped edges typical of epithelial HSV keratitis. They stain irregularly with fluorescein, lesions are bilateral, and lesions react sporadically without any apparent relationship to treatment. ${ }^{4,5}$

Pseudodendrites occasionally may occur in other conditions such as keratoconjunctivitis medicamentosa and healing epithelial defects. Opaque degenerated epithelium or the advancing waves of healing epithelium may assume a dendritiform configuration. These lesions are often shaped like a horizontal $\mathrm{Y}$ or double-ended $\mathrm{Y}$. However, unlike the true herpetic dendrites, these have no repetitively dichotomous branching and no bulbous terminal erosions. Also, staining with fluorescein is either absent or sparse. Further evidence may be obtained by noting the absence of multinucleated giant cells in scrapings and negative results on virologic studies.

The cases reported by us are young males and have no associated ocular or systemic abnormalities, except for associated MGD. The common symptoms were irritation and watering. The duration of symptoms was variable, with symptoms lasting for several years in two patients. Corneal lesions involved the epithelium, were slightly raised, and showed variable branching, usually located in the central and inferotemporal quadrants and showed punctate staining. Serum tyrosine levels were normal in three patients. In patient no. 1, the epithelial lesion reappeared after debridement and corneal scrapings also did not reveal HSV antigen in any of the patients. Lesions promptly resolved after the application of bandage contact lens. However, in view of associated risk of infectious keratitis from extended wear contact lenses, prophylactic weak topical antibiotics were also prescribed.

In MGD, alterations in lipid secretions and abnormal keratinization of the meibomian gland duct orifices, whether through medicinal, hormonal, infectious, or inflammatory influences, have a profound effect on the quality of tear film and on the ocular surface.

Inflammatory mediators accumulate in the tear film, and the inflammation so induced can damage the ocular surface. ${ }^{7}$ The ocular surface manifestations reported in MGD include conjunctival injection, papillary changes, and punctate staining. ${ }^{8}$ We are presenting this interesting feature of pseudodendritic keratitis in patients with MGD. The prompt resolution of these lesions on the application of bandage contact lens suggests that besides inflammatory mechanisms, mechanical rubbing of the inflamed eyelids on the corneal surface may also be contributing as the probable aetiology for these lesions.

To conclude, pseudodendritic keratitis may be seen in association with the MGD. Application of bandage contact lens resulted in prompt resolution of the dendritiform lesions, suggesting that mechanical factor may be a possible aetiology. These lesions are innocuous and elaborate laboratory work-up may be ordered later, in case of nonresponse to treatment of MGD and bandage contact lens.

\section{References}

1 Holland EJ, Mozayeni RM, Schwartz GS. Herpes simplex virus cornea. In: Krachmer JH, Mannis MJ, Holland EJ (eds). Cornea: Cornea and External Disease: Clinical Diagnosis and Management. Mosby Publication: St Louis, MO, 1997, p 1197.

2 Pavan-Langstone D, McCulley JP. Herpes zoster dendritic keratitis. Arch Ophthalmol 1973; 89: 25-29.

3 Leisgang TJ. Corneal complications from herpes zoster ophthalmicus. Ophthalmology 1985; 92: 316-324.

4 Macsai MS, Schwartz TL, Hinkle D, Hummel MB, Mulhern MG, Rootman D et al. Tyrosenemia type II. Nine cases of ocular signs and symptoms. Am J Ophthalmol 2001; 132: 522-527.

5 Bienfang DC, Kuwabara T, Pueschel SM. The Richner-Hanhart syndrome. Report of a case with associated tyrosinemia. Arch Ophthalmol 1976; 94: 1133-1137.

6 Wilson FM. Adverse external ocular effects of topical ophthalmic medications. Surv Ophthalmol 1979; 24 : 57.

7 Solomon A, Dursun D, Lin Z, Xie Y, Macri A, Pflugfelder SC et al. Pro- and anti-inflammatory function of interlukin-1 in tear fluid and conjunctiva of patients with dry eye disease. Invest Ophthalmol Vis Sci 2001; 42: 2283-2292.

8 Driver PJ, Lemp MA. Meibomian gland dysfunction. Surv Ophthalmol 1996; 40: 346. 